\title{
Pathophysiology of Hemolysis in Infections with Hemophilus influenzae Type b
}

Susan B. Shurin, Porter Anderson, Janet Zollinger, and R. Keaney Rathbun

Department of Pediatrics, Case Western Reserve University School of Medicine, Cleveland, Ohio 44106; and Department of Pediatrics, School of Medicine, University of Rochester, Rochester, New York 14642

\begin{abstract}
The capsular polysaccharide of Hemophilus influenzae type b, polyribosyl ribitol phosphate (PRP), is released from growing organisms during human infection and can be found in body fluids. It binds to untreated erythrocytes. Many patients with invasive infections with this organism develop significant hemolysis, but the mechanism has been unclear. We have found that PRP binds to human erythrocytes in vivo. PRP-coated erythrocytes have a shortened circulation time in mice, but do not lyse spontaneously or fix complement. PRP-coated erythrocytes exposed to antiserum to $H$. influenzae type b are undamaged in the absence of complement, but are rapidly and effectively lysed in the presence of an intact complement system both in vitro and in vivo in mice. PRP-coated red cells are taken up by liver and spleen. Antiserum to PRP increases hepatic uptake of PRP-coated red cells more than splenic, and appears to induce intravascular, complementmediated hemolysis, as well as extravascular hemolysis. Patients with invasive infection develop hemolysis when circulating PRP and antibody to PRP are present simultaneously. PRP can sometimes be detected on patient erythrocytes when free PRP is present in serum, but this is an inconsistent finding. The hemolytic anemia that occurs during human infection with $H$. influenzae type b may be due to absorption of PRP to red cells and immune destruction of sensitized erythrocytes. The process requires an intact complement system; both complement-mediated cell lysis and extravascular hemolysis contribute to red cell destruction.
\end{abstract}

\section{Introduction}

Many bacterial species contain antigens that can be adsorbed to untreated erythrocytes and render these modified red cells agglutinable by antibodies to the bacterial antigens. Most, if not all, of these substances are polysaccharides or contain polysaccharides as the antigenically relevant constituent (1). Protein antigens may be adsorbed to red cells treated with tannic acid ("tanned erythrocytes"), but do not bind well to untreated red cells (2). The adsorption of Hemophilus influenzae type b polysaccharides to erythrocytes was described in 1947 (3), and was for many years the basis of immunologic studies of this organism utilizing passive hemagglutination techniques. $H$. influenzae type $\mathrm{b}$ releases its capsular polysaccharide, polyribosyl ribotyl phosphate (PRP) ${ }^{1}$ into the culture medium in which it is grown, and

Dr. Anderson is with the Department of Pediatrics, University of Rochester School of Medicine, Rochester, New York. Address reprint requests to Dr. Shurin, 2074 Adelbert Road, Cleveland, $\mathrm{OH} 44106$.

Received for publication 30 May 1984 and in revised form 4 December 1985.

1. Abbreviations used in this paper: CSF, cerebrospinal fluid; PRP, polyribosyl ribitol phosphate.

J. Clin. Invest.

(c) The American Society for Clinical Investigation, Inc.

0021-9738/86/04/1340/09 \$1.00

Volume 77, April 1986, 1340-1348 into biological fluids such as blood and cerebrospinal fluid (CSF) during natural infections. PRP is the major virulence factor of $H$. influenzae type $b$, and is responsible for enabling the organism to evade phagocytosis, as it does not bind to phagocytic cells and does not activate the alternative pathway of complement (4). Antibody to PRP protects against laboratory and natural infections $(5,6)$. PRP is poorly immunogenic in young children who experience the majority of infectious episodes, but is effective as a vaccine against $H$. influenzae type b infections in most older children and adults $(7,8)$.

An association between anemia and $H$. influenzae type b meningitis was first noted because of a high frequency of blood transfusions given to these patients $(9,10)$. No difference in the severity of anemia was found between patients treated with specific rabbit serum and patients who did not receive the antiserum. A subsequent report attributed hemolytic anemia to administration of immune rabbit serum; many of these patients developed spherocytosis on peripheral blood smear (11). Both reports noted more severe anemia in patients with more severe infectious illnesses. Subsequent studies have confirmed this observation, and noted that anemia on admission is more common in patients with longer prodromal illness (12). The erythrocytes of patients with $H$. influenzae type b meningitis have been found to be less deformable and to have higher levels of carboxyhemoglobin than erythrocytes from patients with other forms of meningitis or from uninfected persons (13). The hemolytic nature of the anemia has been noted, and the possibility that adsorbed bacterial toxins contribute to red cell destruction has been suggested by several authors $(10,12)$. Hypoferremia secondary to acute infection may contribute to the lack of erythropoiesis in response to anemia (14).

The present study explores the effects of exposure to supernatants of $\boldsymbol{H}$. influenzae type b cultures and purified PRP on survival of erythrocytes, and the interaction of erythrocytes coated with adsorbed PRP with antibody and with complement. We have found that PRP adsorbs to erythrocytes in vivo during naturally occurring human infections. PRP-coated erythrocytes have a shortened in vivo survival in mice. In the presence of antibody and complement, brisk hemolysis can be demonstrated in vitro and in vivo. In mice, the liver and spleen are the sites of red cell destruction. In patients with systemic $H$. influenzae type b infections, hemolysis occurs when circulating PRP coincides with antibody production. The simultaneous presence of adsorbed bacterial antigen, specific antibody, and complement on the surface of the red cell result in hemolytic anemia.

\section{Methods}

Bacterial supernatants. $H$. influenzae type b, strain Eagan, was grown to log phase or overnight in culture broth (15), and the medium was sterilized by passage through a Millipore filter (Millipore Corp., Bedford, MA). Medium in which no bacteria had been grown was used as a control. Supernatants from strain Eagan and from a variant, Eagan S-2, which releases $\sim 1 \%$ of the PRP released by Eagan, were used (15). PRP was prepared from the bacterial supernatant as previously described (16).

Sera. High-titer antiserum to $H$. influenzae type b was prepared in 
rabbits $(17,18)$. This serum contains both $\operatorname{IgG}$ and IgM antibody against PRP and antibodies directed against other $H$. influenzae type b antigens.

Three sources of complement were used. Fresh guinea pig serum was found to contain no detectable antibody to PRP by hemagglutination and did not lyse PRP-coated human erythrocytes in the absence of antibody to PRP. Agammaglobulinemic human serum contained no antibody to PRP by hemagglutination, but samples obtained up to $6 \mathrm{wk}$ after gamma-globulin injection contained sufficient isohemagglutinins to produce some lysis of type A or type B erythrocytes. These sera did not lyse type $O$ erythrocytes. C7-deficient human serum was obtained from a patient with no detectable $\mathrm{C7}$ (19), and absorbed with $H$. influenzae type b at $0^{\circ} \mathrm{C}$ for 60 min twice prior to use. All samples were separated within $90 \mathrm{~min}$ of collection, and stored at $-90^{\circ} \mathrm{C}$ in aliquots.

Passive hemagglutination assay for detection of antibody to PRP and $P R P$ on patient erythrocytes. A modification of published methods was employed (17). Fresh human type $\mathrm{O} R \mathrm{Rh}$-negative erythrocytes were collected in acid-citrate-dextrose and washed three times in phosphate-buffered saline (PBS). They were stored up to 2 wk at $4^{\circ} \mathrm{C}$ in Alsever's solution. For antigen sensitization, the cells were suspended in PBS at $1.2 \%$ (vol/vol) with $5.0 \mu \mathrm{g}$ of $\mathrm{PRP} / \mathrm{ml}$, incubated $1 \mathrm{~h}$ at $37^{\circ} \mathrm{C}$, washed three times with PBS to remove unabsorbed antigen, and suspended in PBS at $0.6 \%$. The binding of PRP to the cell surface was stable for at least $2 \mathrm{wk}$, but sensitized cells were usually freshly prepared. Patient cells were stored up to $5 \mathrm{~d}$ in Alsever's solution. Serial twofold dilutions of $25 \mu \mathrm{l}$ of test serum in PBS with $0.25 \%$ bovine serum albumin (BSA) were prepared in U-bottomed microtiter trays, and $25 \mu \mathrm{l}$ of cell suspension was added. As a control for nonspecific agglutination, each serum was diluted in duplicate with unsensitized type $\mathrm{O}, \mathrm{Rh}$-negative red cells. The trays were sealed, mixed, and incubated for $1 \mathrm{~h}$ at $37^{\circ} \mathrm{C}$. Agglutination was read by tipping the tray to a vertical position and observing for several minutes. Unaggregated cells flowed smoothly downward in a stream, and aggregated cells adhered to the bottom or fell together as a clump. The same red cell donor was used for all assays reported because minor variability in titers was found when cells from different type $O$ donors were used.

Detection of PRP in patient samples. Serum PRP was assayed by latex agglutination (Walpole Laboratories, Cranbury, NJ) (20). PRP was detected on the surface of patient erythrocytes by hemagglutination with rabbit antiserum. Washed patient cells were incubated in U-bottomed microtiter plates with dilutions of rabbit antiserum to $H$. influenzae type b, using nonimmune rabbit serum, PRP-coated human erythrocytes, and untreated erythrocytes as controls.

Measurement of PRP in culture supernatants. PRP was measured in the filtered supernatants of $\log$ phase and overnight cultures of $H$. influenzae type b by radioantigen binding inhibition (21).

Immune hemolysis of patient cells. To determine whether adsorbed bacterial antigens not demonstrable by hemagglutination might be present, patient red cells were incubated with immune rabbit serum and guinea pig complement for $60 \mathrm{~min}$ at $37^{\circ} \mathrm{C}$, and free hemoglobin was measured in the supernatant by measuring absorbance at $560 \mathrm{~nm}$. Patient cells were incubated simultaneously with nonimmune rabbit serum to determine nonspecific release of hemoglobin. Immune hemolysis was considered to be present when the mean absorbance of the supernatant of cells incubated with immune serum was greater than 2 standard deviations (SD) above the mean absorbance of the supernatant of cells incubated with nonimmune serum and complement.

Preparation of phagocytes. Monocytes were prepared from buffy coat preparations obtained from freshly prepared human platelet packs obtained on a Celltrifuge cell separator (Fenwal, Deerfield, IL) in the University Hospitals Blood Bank. The mononuclear cell layer was prepared on a Ficoll-Hypaque gradient (22), and depleted of $T$ lymphocytes by rosetting with sheep erythrocytes (23). The resulting preparation contained $82-86 \%$ esterase-positive cells, which were suspended to $1 \times 10^{8} / \mathrm{ml}$ Hanks' with calcium and magnesium.

Neutrophils were prepared by Ficoll-Hypaque gradient centrifugation from normal human donors. Erythrocytes were removed by hypotonic lysis, and the cells suspended to $1 \times 10^{8} / \mathrm{ml}$ Hanks' with calcium and magnesium.
In vitro hemolysis and erythrophagocytosis. Washed human type $\mathrm{O}$, $\mathrm{Rh}$-negative erythrocytes were labeled with ${ }^{51} \mathrm{Cr}$ by incubating $10^{9} \mathrm{red}$ cells/ml with $100 \mu \mathrm{Ci}$ of $\mathrm{Na}_{2}{ }^{51} \mathrm{CrO}_{4}$ (New England Nuclear, Boston, MA) for $30 \mathrm{~min}$ at $20^{\circ} \mathrm{C}$, and washed three times in PBS. Labeled red cells were sensitized with bacterial antigens by incubating $1 \times 10^{8}$ erythrocytes in $1 \mathrm{ml}$ of culture medium, bacterial supernatant, PBS containing PRP, or PBS alone for $60 \mathrm{~min}$ at $37^{\circ} \mathrm{C}$, and washing three times in PBS. Between 0.001 and $10.0 \mu \mathrm{g}$ of PRP/ml was added. The optimal concentration of $5.0 \mu \mathrm{g} / \mathrm{ml}$ was used for most experiments. Sensitized erythrocytes were incubated with Hanks' or heat-inactivated rabbit antiserum to $H$. influenzae type b for $30 \mathrm{~min}$ at $4^{\circ} \mathrm{C}$, and $0.1-\mathrm{ml}$ aliquots containing $1 \times 10^{7}$ erythrocytes were placed in V-bottom microtiter plates. Triplicate samples of labeled, sensitized erythrocytes then received $0.01 \mathrm{ml}$ of buffer, fresh or heat-inactivated guinea pig complement, agammaglobulinemic human serum, or absorbed C7-deficient human serum. The C7-deficient serum contained no detectable $\mathrm{C} 7$, and had a total hemolytic complement $\left(\mathrm{CH}_{50}\right)$ of zero. The $\mathrm{C} 3$ level was $163 \mathrm{mg} / \mathrm{dl}$. Microtiter trays were sealed, mixed, and incubated for $1 \mathrm{~h}$ at $37^{\circ} \mathrm{C}$. The cells were then pelleted, and the supernatant aspirated and counted in a gamma-counter (Packard Instrument Co., Downers Grove, IL) to determine spontaneous and serum-dependent ${ }^{51} \mathrm{Cr}$ release. The cell pellet was resuspended with 1 $\times 10^{7}$ monocytes or neutrophils in $0.1 \mathrm{ml}$, the trays were resealed, and incubation continued for $2 \mathrm{~h}$ at $37^{\circ} \mathrm{C}$. The cells were pelleted, and the supernatant fluid aspirated and counted to determine extracellular release of ${ }^{51} \mathrm{Cr}$. Free erythrocytes were lysed with $0.87 \% \mathrm{NH}_{4} \mathrm{Cl}$, and the phagocyte pellet was counted to determine intracellular ${ }^{51} \mathrm{Cr}$, or erythrophagocytosis. Results were expressed as the percentage of counts in the sample compared to the counts released by $3 \%$ acetic acid ( $100 \%$ lysis).

Particle ingestion. Emulsions of phthalate oil containing oil red $\mathrm{O}$ and stabilized with $20 \mathrm{mg}$ of gelatin/ml were prepared by sonication by a modification of the method of Stossel et al. (24). Particles were prepared with culture medium, with $H$. influenzae type b culture supernatant, and with $5.0 \mu \mathrm{g}$ of $\mathrm{PRP} / \mathrm{ml} \mathrm{PBS}$ with $1 \mathrm{mM} \mathrm{Ca}^{2+}$ and $\mathrm{Mg}^{2+}$. Antigencoated oil droplets were opsonized with rabbit antiserum to $H$. influenzae type b, guinea pig complement, C7-deficient human serum, or with both antibody and complement for $30 \mathrm{~min}$ at $37^{\circ} \mathrm{C}$, and then fed to neutrophils and monocytes for $5 \mathrm{~min}$ at $37^{\circ} \mathrm{C}$. Uningested oil droplets were removed by centrifugation; the ingested dye-containing oil was extracted from the washed cell pellet with dioxane and quantitated spectrophotometrically at $524 \mathrm{~nm}$.

In vivo survival of erythrocytes in mice. Adult inbred C57 black mice weighing 27-29 $\mathrm{g}$ were bled by retroorbital puncture. Blood was obtained in acid-citrate-dextrose from two mice and labeled with ${ }^{51} \mathrm{Cr}$ as described above. Control erythrocytes were treated with Hanks' BSS. PRP-coated red cells were prepared by incubation with $5.0 \mu \mathrm{g}$ of $\mathrm{PRP} / \mathrm{ml}$ for $1 \mathrm{~h}$ at $37^{\circ} \mathrm{C}$. Opsonized erythrocytes were prepared by treating PRP-coated red cells with heat-inactivated rabbit anti- $H$. influenzae type $b$ antiserum for $30 \mathrm{~min}$ at $4^{\circ} \mathrm{C}$. Four to six mice in each group were injected with 0.03 $\mathrm{ml}$ of packed labeled erythrocytes, or $\sim 3 \times 10^{5}$ red cells per mouse, into the tail vein. Duplicate samples of $0.025 \mathrm{ml}$ of blood were obtained by retroorbital puncture beginning immediately after injection. The initial sample was designated zero time, and considered to represent $100 \%$ survival for purposes of comparison with subsequent samples. The total dose of ${ }^{51} \mathrm{Cr}$ administered was calculated by assuming a total blood volume of $2.5 \mathrm{ml}$ per mouse. The $0.025-\mathrm{ml}$ sample volume represents $1 \%$ of the total blood volume. $5 \mathrm{~d}$ after injection, animals were killed, and liver, spleen, lungs, and kidneys were removed. All organs were weighed and counted in a gamma-counter.

Patient material. A retrospective chart review was made to ascertain the prevalence of anemia in septicemic children. All patients with positive blood cultures were identified from a chronological log maintained in the Bacteriology Laboratory at Rainbow Babies' and Children's Hospital; patients with positive cultures between 1 January 1982 and 30 June 1983 were included. Hospital charts were reviewed to determine the prevalence of anemia. Where hospital charts could not be located, laboratory data was retrieved from computerized reports in the central Hematology laboratory at University Hospitals of Cleveland. Names and hospital numbers were checked against records of patients with known 
hemoglobinopathies and malignancies maintained in the Pediatric Hematology office. Blood smears were reviewed on all patients, and microcytosis and evidence of hemoglobinopathy were specifically noted. Anemia was defined as hemoglobin values less than 2 SD below the mean normal for age (25). Because not all patients had repeat blood counts performed, our data represent the minimum prevalence of anemia in this population. Where serial blood counts were obtained, a decrease in hemoglobin of $>0.5 \mathrm{~g} / \mathrm{dl}$ per $24 \mathrm{~h}$ was considered significant even if the hemoglobin did not fall below the normal range.

10 patients were studied prospectively after blood cultures yielded $H$. influenzae type b. Eight patients had meningitis, with simultaneous positive spinal fluid cultures. Two had epiglottitis. Blood samples were obtained on the day the cultures were noted to be positive, which was within $24 \mathrm{~h}$ of admission to the hospital in nine patients and at $36 \mathrm{~h}$ in the tenth patient. Blood samples were obtained on alternate days for hemoglobin, reticulocyte count, determination of serum PRP, red cellassociated PRP, and serum anti-PRP antibody. On the fifth hospital day, haptoglobin, $\mathrm{CH}_{\mathbf{5 0}}$, direct antiglobulin test, urinary hemoglobin and hemosiderin were measured. G6PD screens were performed on all patients when the reticulocyte count was $<5 \%$.

Statistical methods. Means, variances, linear regressions, correlation coefficients, confidence intervals, and significance tests were performed with formulas entered into a Hewlett-Packard HP 27 programmable calculator (Hewlett-Packard Co., Palo Alto, CA). The equations for statistical tests and statistical tables were obtained from standard sources (26).

\section{Results}

In vitro studies of hemolysis and erythrophagocytosis. Treatment of erythrocytes with culture medium, supernatants of cultures of $H$. influenzae type b or purified PRP did not induce ${ }^{51} \mathrm{Cr}$ release in the presence or absence of antibody to $H$. influenzae type b, or in the presence of complement without antibody (Table I). Erythrocytes treated with bacterial antigens (PRP or culture supernatants) released over $75 \%$ of their ${ }^{51} \mathrm{Cr}$ in the presence of rabbit antiserum and complement. The extent of complementmediated hemolysis induced by exposure to bacterial supernatants was identical to that produced by purified PRP. Bacterial supernatants of $H$. influenzae type b, strain Eagan, contained $26 \mu \mathrm{g}$ of PRP/ml at log phase, and $160 \mu \mathrm{g} / \mathrm{ml}$ when grown overnight, while supernatants of strain Eagan S-2 contained $0.17 \mu \mathrm{g}$ of $\mathrm{PRP} / \mathrm{ml}$ at $\log$ phase and $2.8 \mu \mathrm{g}$ of $\mathrm{PRP} / \mathrm{ml}$ when grown overnight. Erythrocytes treated with culture media without bacterial antigens did not undergo lysis in the presence or absence of antibody and complement, implying that the hemolytic properties were due to bacterial products. The dependence of hemolysis upon terminal complement components was demonstrated by the failure of $\mathrm{C} 7$-deficient serum to induce chromium release in the presence of antibody.

Antibody-dependent, complement-mediated hemolysis was proportional to the concentration of PRP with which erythrocytes were pretreated (Fig. 1). Neither hemagglutination nor specific ${ }^{51} \mathrm{Cr}$ release was detectable $<0.025 \mu \mathrm{g}$ of $\mathrm{PRP} / \mathrm{ml}$. The extent of ${ }^{51} \mathrm{Cr}$ release increased with the PRP concentration up to $5.0 \mu \mathrm{g} / \mathrm{ml}$, above which further increases did not induce more extensive hemolysis. Supernatants from $H$. influenzae type b strain Eagan S-2 grown to log phase containing $0.17 \mu \mathrm{g}$ of PRP/ $\mathrm{ml}$ induced $15 \%{ }^{51} \mathrm{Cr}$ release from sensitized red cells treated with antibody and complement. Supernatants from overnight cultures of Eagan S-2 containing $2.8 \mu \mathrm{g}$ of $\mathrm{PRP} / \mathrm{ml}$ induced as much hemolysis as supernatants from Eagan at log phase or overnight, and as much as $5 \mu \mathrm{g}$ of purified PRP/ml.

Neither monocytes nor neutrophils induced extracellular hemolysis during a 2-h incubation with sensitized erythrocytes exposed to antiserum or C7-deficient serum. Erythrophagocytosis by monocytes and polymorphonuclear leukocytes (PMN) could not be demonstrated in the presence of antiserum or complement alone. When both antiserum and intact complement were present, hemolysis was virtually complete, and ingestion could not be assessed.

Quantitative ingestion of oil droplets containing bacterial antigens was greatly enhanced by treatment of the particles with both antiserum and complement (Table II). Gelatin particles were ingested by both monocytes and neutrophils at a low rate without opsonization. The rate of particle ingestion was enhanced by antiserum and complement only if bacterial supernatant or PRP was present. Phagocytosis of oil droplets was enhanced by bacterial supernatants which contained only small amounts of PRP. Eagan S-2 log-phase supernatants increased antibody-mediated ingestion as much as supernatants from S-2 overnight, Eagan log-phase and Eagan overnight cultures, although it in-

Table I. In Vitro Hemolysis of Erythrocytes: Percent ${ }^{51} \mathrm{Cr}$ Release

\begin{tabular}{|c|c|c|c|c|c|c|}
\hline \multirow[b]{3}{*}{ Serum source } & \multicolumn{6}{|c|}{ Treatment of erythrocytes } \\
\hline & \multirow[b]{2}{*}{ Culture medium } & \multicolumn{2}{|c|}{ Hib Eagan culture supernatant } & \multicolumn{2}{|c|}{ Hib Eagan S-2 culture supernatant } & \multirow{2}{*}{$\begin{array}{l}\text { PRP } \\
(5 \mu \mathrm{g} / \mathrm{ml})\end{array}$} \\
\hline & & Log phase & Overnight & Log phase & Overnight & \\
\hline & \% ${ }^{31} \mathrm{Cr}$ release & \% ${ }^{\text {II }} \mathrm{Cr}$ release & ${ }^{9}{ }^{51} \mathrm{Cr}$ release & $\%{ }^{s 1} \mathrm{Cr}$ release & $\%{ }^{51} \mathrm{Cr}$ release & $\%{ }^{\text {II }} \mathrm{Cr}$ release \\
\hline None & $4 \pm 1$ & $3 \pm 2$ & $2 \pm 1$ & $2 \pm 2$ & $3 \pm 1$ & $4 \pm 2$ \\
\hline Antiserum & $4 \pm 1$ & $4 \pm 2$ & $4 \pm 1$ & $3 \pm 1$ & $3 \pm 2$ & $3 \pm 1$ \\
\hline Guinea pig complement & $3 \pm 2$ & $2 \pm 1$ & $3 \pm 2$ & $4 \pm 1$ & $3 \pm 1$ & $4 \pm 2$ \\
\hline Human complement & $4 \pm 2$ & $3 \pm 2$ & $2 \pm 1$ & $3 \pm 1$ & $4 \pm 1$ & $3 \pm 2$ \\
\hline C7-deficient human serum & $4 \pm 4$ & $2 \pm 1$ & $3 \pm 2$ & $3 \pm 2$ & $2 \pm 1$ & $4 \pm 2$ \\
\hline Antiserum + complement & $3 \pm 1$ & $75 \pm 7^{*}$ & $77 \pm 7^{*}$ & $25 \pm 4^{*}$ & $78 \pm 6^{*}$ & $76 \pm 6$ \\
\hline
\end{tabular}

Heat-inactivated, high-titer rabbit antiserum to $H$. influenzae type b (Hib) was the source of antibody. Agammaglobulinemic human serum and guinea pig serum were used as sources of complement. C7-deficient human serum was absorbed with $\boldsymbol{H}$. influenzae type b prior to use. Culture supernatants from strain Eagan and Eagan S-2 were tested after growth to log phase and after overnight growth. Mean $\pm \operatorname{SD}(n=9)$. ${ }^{*} P<0.001$. 


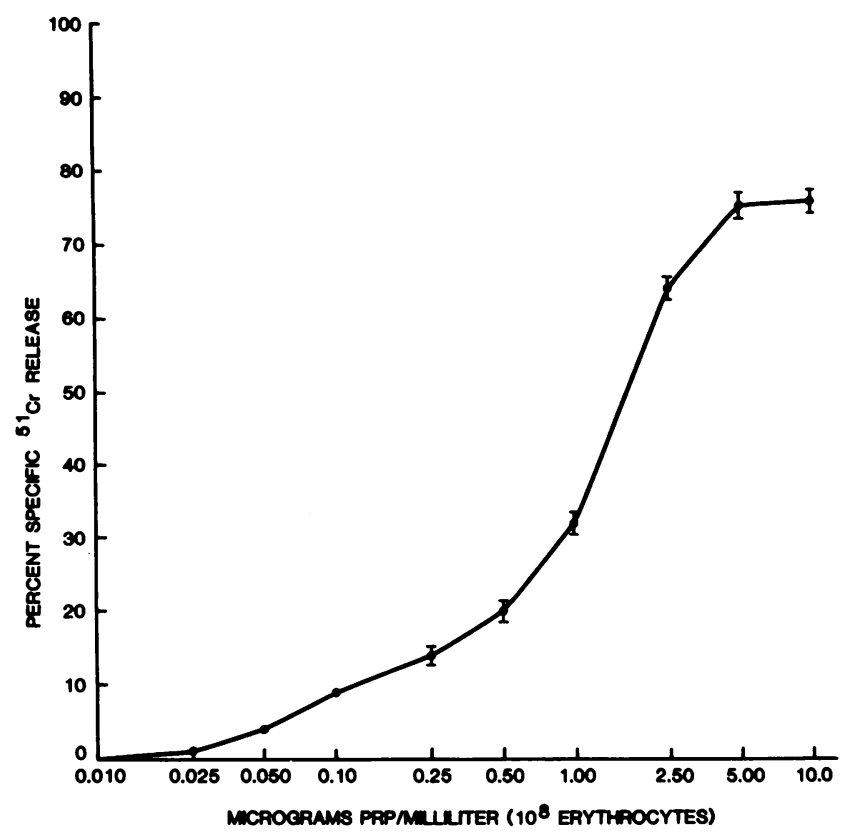

Figure 1. Effect of PRP concentration on specific ${ }^{51} \mathrm{Cr}$ release. Type $\mathrm{O}$, Rh-negative human erythrocytes were labeled with ${ }^{51} \mathrm{Cr}$, incubated with varying concentrations of PRP for $60 \mathrm{~min}$ at $37^{\circ} \mathrm{C}$, washed, and incubated with rabbit antiserum (1:400) and guinea pig complement (1:100) for $60 \mathrm{~min}$ at $37^{\circ} \mathrm{C}$. Hemagglutination and release of ${ }^{51} \mathrm{Cr}$ into the supernatant fluid were determined. Specific ${ }^{51} \mathrm{Cr}$ release was calculated by subtracting the counts released by incubation of cells in heatinactivated guinea pig complement from the counts released in the presence of antibody and intact complement, dividing by the number of counts released in the presence of $3 \%$ acetic acid, and multiplying by 100 .

duced suboptimal complement-mediated immune hemolysis of erythrocytes (Table I).

In vivo erythrocyte survival and hemolysis. Treatment of red blood cells with PRP resulted in rapid clearance of $12 \%$ of the cells from the circulation of mice (Fig. 2). Between $1 \mathrm{~h}$ and $5 \mathrm{~d}$, the rate of clearance of ${ }^{51} \mathrm{Cr}$-labeled cells was equivalent with ( $0.41 \%$ per hour) and without $(0.37 \%$ per hour) treatment with PRP. PRP-coated erythrocytes accumulated in the liver and spleen (Table III). Pretreatment of PRP-coated red cells with rabbit antiserum resulted in clearance of $32 \%$ of the cells within the first hour, and a more rapid rate of destruction of the remaining cells than of control or PRP-coated red cells $(0.53 \%$ per hour). Exposure of PRP-coated erythrocytes to rabbit antiserum further increased accumulation of ${ }^{51} \mathrm{Cr}$ in the liver; splenic ${ }^{51} \mathrm{Cr}$ was the same whether or not PRP-coated cells were treated with antiserum. No increase in pulmonary ${ }^{51} \mathrm{Cr}$ occurred when cells were treated with PRP with or without antiserum. By adding the ${ }^{51} \mathrm{Cr}$ remaining in the blood to that recovered from the organs, we were able to account for $99 \%$ of the administered counts in the control animals, $112 \%$ of the counts in the animals that received PRP-coated cells, and only $80 \%$ of the counts in animals that received PRP antiserum-treated cells. The lower recovery in the group given antibody-treated cells implies that $\sim 20 \%$ of the red cells underwent intravascular hemolysis with loss of released ${ }^{51} \mathrm{Cr}$ in the urine, which was not measured. This is consistent with other evidence that complement activation is important in this process, and suggests that both $\mathrm{C} 3 \mathrm{~b}$ and hemolytic C9 participate in red cell destruction.

All mice that received PRP-coated cells treated with antiserum became tachypneic. One mouse died $3 \mathrm{~d}$ after injection of red cells, and the remaining mice recovered markedly more slowly from ether anesthesia administered for bloodletting than mice in the other two groups, whose clinical picture did not change. The clinical changes were not seen until $3 \mathrm{~d}$ after injection of erythrocytes. The lung weights of the animals that survived to $5 \mathrm{~d}(245 \pm 16 \mathrm{mg})$ were significantly greater than those of mice receiving control $(142 \pm 45 \mathrm{mg})$ or PRP-coated red cells $(206 \pm 57 \mathrm{mg})$. The lungs were edematous but not hemorrhagic or consolidated. Liver and spleen were not enlarged, despite the significant increase in the ${ }^{51} \mathrm{Cr}$ retained by these organs.

Hematologic status of septicemic children. Patients with $H$. influenzae type $b$ infections had a markedly higher incidence of anemia on admission to the hospital $(49 \%)$ than did patients with septicemia owing to Neisseria meningitidis (none) or Streptococcus pneumoniae (9\%) (Table IV). Meningitis was more prevalent in patients with $N$. meningitidis or $H$. influenzae type b septicemia than in patients with $S$. pneumoniae septicemia, most of whom had an uncomplicated hospital course. Because many patients did not have hemoglobin determinations after admission, these data represent the minimal incidence of anemia in this population. Of nonanemic patients having subsequent blood counts, anemia was more prevalent in patients with $H$. influenzae type b infection than in patients infected with $N$. meningitidis or S. pneumoniae. Anemia developed in two-thirds of patients with $H$. influenzae type b infections, but none with $N$. meningitidis and $11 \%$ of patients with $S$. pneumoniae infections.

Anemia was also more severe in patients with $H$. influenzae type b infections (Table IV). No patients with septicemia resulting from other organisms had hemoglobin values $<9 \mathrm{~g} / \mathrm{dl}$, while

Table II. Phagocytosis of Oil Droplet Emulsions by Neutrophils

\begin{tabular}{lllcc}
\hline & Particle emulsion & & & \\
\cline { 2 - 5 } Serum source & Culture medium & Hib Eagan supernatant & Hib Eagan S-2 supernatant & PRP (5.0 $\mu \mathrm{g} / \mathrm{ml})$ \\
\hline & $\mu \mathrm{g}$ oil/min per $10^{7} \mathrm{pmn}$ & $\mu \mathrm{g}$ oil/min per $10^{7} \mathrm{pmn}$ & $\mu \mathrm{g}$ oil/min per $10^{7}$ pmn & $\mu \mathrm{g}$ oil/min per $10^{7}$ pmn \\
Antiserum & $2 \pm 1$ & $8 \pm 2$ & $9 \pm 2$ & $9 \pm 2$ \\
Complement & $2 \pm 1$ & $9 \pm 3$ & $8 \pm 2$ & $9 \pm 1$ \\
Antiserum + complement & $3 \pm 1$ & $64 \pm 4^{*}$ & $62 \pm 3^{*}$ & $61 \pm 3 \ddagger$ \\
\hline
\end{tabular}

Rabbit antiserum to $H$. influenzae type b (Hib) was used as a source of antibody. Guinea pig complement was used as a source of complement. Mean \pm SD. $* P<0.001$. $¥$ Hib Eagan and Eagan $S-2$ supernatants were tested at log phase and after overnight growth. No difference in ingestion rates were found between log-phase and overnight culture supernatants, and results for the organisms are pooled. 


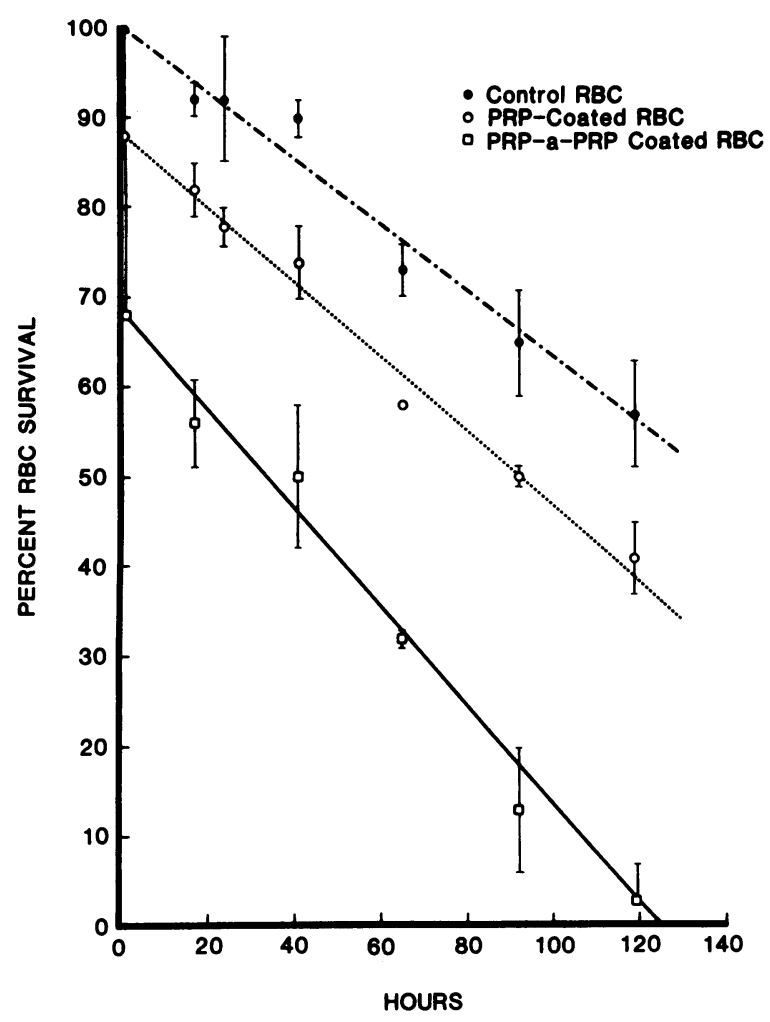

Figure 2. Survival of ${ }^{51} \mathrm{Cr}$-labeled erythrocytes in mice. Autologous erythrocytes (RBC) were treated with balanced salt solution, PRP (5.0 $\mu \mathrm{g} / \mathrm{ml}$ ), or PRP and heat-inactivated rabbit antiserum to $H$. influenzae type b before reinfusion into C57 black mice. Results are expressed as mean \pm SD of duplicate samples at each time in four to six mice, standardized to red cell survival immediately after infusion $=100 \%$.

$28 \%$ of patients with $H$. influenzae type b infections had either admission or subsequent hemoglobin levels $<9 \mathrm{~g} / \mathrm{dl}$. Both the mean admission hemoglobin levels and the mean hemoglobin nadir were significantly lower in patients with $H$. influenzae type $b$ infections, with a wider range of values than in patients with septicemia owing to $N$. meningitidis or $S$. pneumoniae.

Of 10 patients observed prospectively, three were anemic on admission, and three developed anemia in the hospital (Table V). All six anemic patients had antigenemia persisting beyond the third hospital day, and simultaneously circulating antibody to PRP. PRP adsorbed to the patient's erythrocytes was detectable by hemolysis in four patients and by hemagglutination in two of the four. One patient had a transiently positive nongamma direct antiglobulin test prior to the fall in hemoglobin, but all other direct antiglobulin tests were negative. Urinary he-

Table III. Percentage of Administered ${ }^{5 I} \mathrm{Cr}$ Retained in Organs 5 d after Injection

\begin{tabular}{llll}
\hline $\begin{array}{l}\text { Treatment of } \\
\text { erythrocytes }\end{array}$ & Liver & Spleen & Lungs \\
\hline None & $15.9 \pm 3.8$ & $20.5 \pm 4.9$ & $4.8 \pm 1.4$ \\
PRP & $30.9 \pm 5.9$ & $34.5 \pm 2.1(P<0.05)$ & $5.7 \pm 1.4$ \\
PRP antiserum & $36.7 \pm 7.5(P<0.01)^{*}$ & $31.8 \pm 6.2(P<0.05)$ & $7.4 \pm 2.9$
\end{tabular}

Mean $\pm \operatorname{SD}(n=3)$.

* Significantly different from control and from PRP-treated rbc. mosiderin was demonstrable on the fifth day in three of the five patients with anemia, but urinary free hemoglobin was not found in any patient on day 5 . Serum haptoglobin in these six patients ranged from 15 to $50 \mathrm{mg} / \mathrm{dl}$ (normal range $30-205 \mathrm{mg} / \mathrm{dl}$ ). $\mathrm{CH}_{50}$ was normal in all six patients. The course of a representative anemic patient is shown in Fig. 3.

Of the four nonanemic patients, three were $<1 \mathrm{yr}$ of age (Table VI). Two of the infants had persistent antigenemia detectable beyond the third hospital day; the third cleared circulating PRP by the second hospital day, but only one of the three infants developed detectable antibody to PRP by the time of discharge $2 \mathrm{wk}$ after admission. The course of one of these patients is shown in Fig. 4. The fourth patient, aged $19 \mathrm{mo}$, had no detectable PRP in serum on admission, and had measurable antibody to PRP on the third hospital day. In none of these patients were circulating PRP and antibody to PRP detectable simultaneously. All four patients who did not develop anemia had serum haptoglobin $>100 \mathrm{mg} / \mathrm{dl}$, normal $\mathrm{CH}_{50}$, negative direct antiglobulin tests, and urine negative for hemoglobin and hemosiderin.

In vitro immune hemolysis of patient red cells could be demonstrated in all three patients in whom passive hemagglutination indicated that PRP was present on the surface of the red cells, and in an additional three patients with negative hemagglutination tests. In all patients in whom in vitro immune hemolysis was present, PRP was identifiable in simultaneous serum samples. PRP could not be identified on two patients' erythrocytes despite its presence in serum. In vitro immune hemolysis was more likely to be demonstrable early in the patient's hospitalization, and did not persist in any patient beyond the third hospital day. Thus, in vivo sensitization of red cells was an inconsistent accompaniment of antigenemia.

\section{Discussion}

The capsular polysaccharide, PRP, is a critical virulence factor in systemic infections with $H$. influenzae type b. PRP is poorly antigenic in young children, a feature that limits the use of PRP as a vaccine to children over the age of $2 \mathrm{yr}(6-8)$. During systemic infection, PRP is released into the circulation, and can be found in blood, urine, and CSF of patients with meningitis (21). In patients treated with antibiotics, bacteremia usually clears rapidly, but PRP can be detected for varying lengths of time after sterilization of blood. Some patients clear PRP from the blood within a few days of institution of effective therapy, while others have prolonged antigenemia that may persist beyond the time of discharge from the hospital, long after they are clinically well. Prolonged antigenemia is most frequent in children who do not develop an antibody response, and in those who have a severe clinical course. Patients with prolonged antigenemia who develop an antibody response have both free PRP and PRP complexed to antibody demonstrable in the presence of free antibody specific for PRP (21).

Complement activation by PRP requires the presence of specific antibody (4). The failure of purified PRP to activate the alternative pathway of complement may account for the virulence of type b compared to the other five serotypes of $H$. influenzae, a and c-f (27-29). Somatic antigens may activate the alternative pathway of complement, but are largely unexposed in the presence of an intact capsule. Complement is not activated by whole organisms in EGTA-chelated serum. The lack of non- 


\begin{tabular}{lccc}
\hline & Infecting organism & & \\
\cline { 2 - 4 } & N. meningitidis & S. pneumoniae & H. influenzae type b \\
\hline Total number of patients* & 11 & 46 & 43 \\
Patients with meningitis $(n) \ddagger$ & $9(82 \%)$ & $4(9 \%)$ & $28(65 \%)$ \\
Patients anemic on admission $(n)$ & $0(9 \%)$ & $4(9 \%)$ & $21(49 \%)$ \\
Patients developing anemia $(n) \S$ & $0 / 5(0 \%)$ & $1 / 10(10 \%)$ & $8 / 12(67 \%)$ \\
Total patients with anemia $(n)$ & $0(0 \%)$ & $5(11 \%)$ & $29(67 \%)$ \\
Patients with $\mathrm{Hgb}<9 \mathrm{~g} / d l(n)$ & $0(0 \%)$ & $0(0 \%)$ & $12(28 \%)$ \\
Hgb on admission $(g / d l)^{\|}($mean $\pm \mathrm{SD})$ & $12.3 \pm 0.6$ & $12.1 \pm 0.9$ & $10.5 \pm 1.8$ \\
Hgb nadir $(g / d l)^{\prime \prime}$ & $12.3 \pm 0.6$ & $12.0 \pm 0.9$ & $9.4 \pm 2.5$
\end{tabular}

* Total number of septicemic patients without other significant hematologic disorder. Patients with malignancies, sickle cell syndromes, G6PD deficiency, and mean corpuscular volume $<80 \mathrm{fl}$ have been excluded from analysis. $¥$ Meningitis was defined as CSF culture positive for the same organism isolated from the bloodstream. CSF pleocytosis alone was not considered meningitis. § Patients not anemic on admission who had a repeat hemoglobin $(\mathrm{Hg})$ determination performed. Patients developing anemia are those whose subsequent hemoglobin level dropped $>0.5$ $\mathrm{g} / \mathrm{dl} \mathrm{d}$ and was $<10.5 \mathrm{~g} / \mathrm{dl}$. "Admission and nadir mean hemoglobin values for patients with $H$. influenzae septicemia were significantly different from values for patients with $N$. meningitidis and with $S$. pneumoniae septicemia $(P<0.001)$.

immune complement-mediated lysis of red cells exposed to crude bacterial supernatants suggests that somatic antigens released into the culture medium (30) either are not adsorbed to erythrocytes under these conditions or do not activate the alternative pathway of complement once adsorbed to the erythrocytes. Logphase bacterial culture supernatants of strain Eagan contain five times, and overnight culture supernatants contain over 30 times as much PRP as is needed to produce maximal erythrocyte sensitization in a purified state $(15,31)$. Culture supernatants of Eagan S-2, a variant strain of Hib producing $1 \%$ of the PRP released by wild-type strain Eagan, induced a lower level of immune hemolysis that was slightly higher than that induced by purified PRP at a concentration equivalent to that present at log phase. Overnight Eagan S-2 culture supernatants induced the maximal extent of hemolysis, corresponding to that seen with an equivalent concentration of purified PRP. The fact that PRP and supernatant induce identical patterns of hemolysis, and that the extent of hemolysis depends on the amount of PRP released by the organisms, strongly suggests that PRP is the major antigen in the bacterial supernatant which adsorbs to erythrocytes and shortens their survival in vivo.
The ability of certain viruses, bacteria, and bacterial products to adsorb to erythrocytes has been known for many years. Staphylococcus aureus and Vibrio cholera directly induce clumping of red cells (1). Hemagglutination and hemolysis of coated erythrocytes in the presence of antibodies to adsorbed antigens have been the basis of many assays in microbiology developed long before either the antigens or the antibodies were characterized. Immune agglutination of red cells in the presence of adsorbed bacterial products was first described in 1947 using $H$. influenzae type b (3). Virtually all of the substances that adsorb to untreated erythrocytes are polysaccharides or lipopolysaccharides $(1,32)$.

Although the ability of bacterial products to adsorb to erythrocytes in vitro is a useful laboratory tool, it does not imply that similar phenomena occur in vivo, or that survival of coated erythrocytes is in any way affected. The Vi antigen of Salmonella adsorbs to red cells of many species of animals. Injection of $\mathrm{Vi}$ antigen-coated erythrocytes into rabbits stimulates production of antiserum with anti-Vi specificity, devoid of antibodies to other Salmonella antigens (33). This appears to be an effective method of antigen presentation. Sensitized erythrocytes are rap-

Table V. Patients with $H$. influenzae Type b Infection Who Developed Anemia

\begin{tabular}{|c|c|c|c|c|c|c|}
\hline Age $(m o)$ & $10^{*}$ & 16 & 6 & $16 \ddagger$ & $20 \ddagger$ & 7 \\
\hline Duration of antigenemia $(d)$ & 14 & 4 & 14 & 3 & 4 & 5 \\
\hline Onset of detectable antibody (day) & 2 & $1 \S$ & 2 & $1 \S$ & 1 & 1 \\
\hline PRP on patient erythrocytes by hemagglutinin & + & - & + & - & - & - \\
\hline PRP on patient erythrocytes by immune hemolysis & + & + & + & + & - & - \\
\hline Admission hemoglobin & 10.6 & 8.8 & 8.4 & 7.8 & 13.0 & 12.8 \\
\hline Nadir hemoglobin & 7.6 & 8.2 & 7.6 & 7.4 & 9.8 & 7.8 \\
\hline Urinary hemosiderin (day 5) & + & + & - & + & - & - \\
\hline Serum haptoglobin (day 5) & 22 & 29 & 50 & 15 & 16 & 0 \\
\hline Complement $\left(\mathrm{CH}_{\mathbf{5 0}}\right) \pi$ & 216 & 281 & 172 & 192 & 184 & 210 \\
\hline
\end{tabular}

* Patient's course shown in Fig. 3. ‡ Patients with epiglottitis. § Antibody detectable on admission. " Normal range 30-305 mg/dl. I Normal range 134-350 U. 


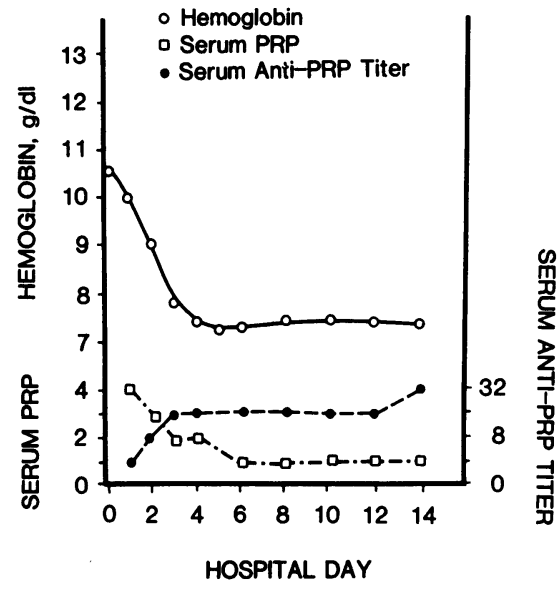

Figure 3. Anemia developing in a patient with $H$. influenzae type b meningitis. The hemoglobin value serum PRP by latex agglutination and serum anti-PRP titers by passive hemagglutination are plotted against the time in hospital for this child who hemolyzed abruptly while PRP and anti-PRP were detectable in serum simultaneously.

idly cleared from immune rabbits. Chicken erythrocytes can be sensitized in vivo during infection with Salmonella gallinarum (34). In vivo sensitization of erythrocytes by lipopolysaccharide of two different strains of Escherichia coli has been demonstrated in human infants with enteritis without invasive infection (35). $E$. coli lipopolysaccharide induces spherocytosis of human cells in vitro, but this has not been shown in vivo $(36,37)$. Nonimmune rabbits infected with type I pneumococcus develop in vivo erythrocyte sensitization, spherocytosis, and hemolysis (38).

In several disease entities, specific interaction between the products of microorganisms and components of the host immune system with erythrocytes appears to contribute significantly to development of hemolytic anemia $(1,30)$. The anemia that develops in West African children with acute Plasmodium falciparum malaria is most marked during the period shortly after treatment, when parasitemia has cleared, and the direct antiglobulin test is positive (39-43). Antigen-antibody complexes adsorb to the surface of erythrocytes, but neither antigen nor antibody alone adsorbs. C3d is found very commonly. Severe

Table VI. Patients with $H$. influenzae Type b

Infection Who Did Not Develop Anemia

\begin{tabular}{|c|c|c|c|c|}
\hline Age $(m o)$ & 19 & 8 & 7 & $6^{*}$ \\
\hline Duration of antigenemia $(d)$ & 0 & 2 & 7 & 14 \\
\hline $\begin{array}{l}\text { Onset of detectable } \\
\text { antibody (day) }\end{array}$ & 2 & 4 & 0 & 0 \\
\hline $\begin{array}{l}\text { PRP on patient erythrocytes } \\
\text { by hemagglutinin }\end{array}$ & - & - & - & + \\
\hline $\begin{array}{l}\text { PRP on patient erythrocytes } \\
\text { by immune hemolysis }\end{array}$ & - & - & + & + \\
\hline Admission hemoglobin & 11.8 & 12.1 & 11.3 & 12.5 \\
\hline Nadir hemoglobin & 11.7 & 12.1 & 10.9 & 12.3 \\
\hline Urinary hemosiderin (day 5) & - & - & - & - \\
\hline Serum haptoglobin (day 5) & 165 & 183 & 128 & 156 \\
\hline Complement $\left(\mathrm{CH}_{30}\right)$ & 198 & 206 & 257 & 202 \\
\hline
\end{tabular}

* Patient's course shown in Fig. 4.

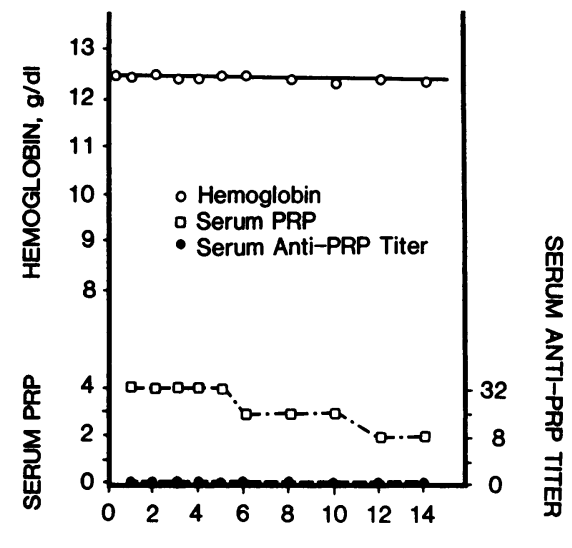

HOSPITAL DAY

Figure 4. A nonanemic patient with $H$. influenzae type b meningitis. Hemoglobin serum PRP and serum anti-PRP titers are plotted against time in hospital for this child whose hemoglobin remained stable. Serum PRP was still present at the time of discharge, but no anti-PRP was detectable during the child's hospital stay.

hemolytic anemia is associated with $\mathrm{C} 3 \mathrm{~b}$ on the surface of erythrocytes and with erythrophagocytosis by monocytes. ${ }^{51} \mathrm{Cr}$-labeled red cells have a reduced life span for over a month after complete eradication of malarial parasites, and are concentrated in the spleen but not in the liver. Evidence of intravascular hemolysis has not been sought.

Adsorption of antigen-antibody complexes to the red cell surface with in vivo sensitization has also been demonstrated in patients with African trypanosomiasis (44) and kala azar (45), and in Trypanosoma bruceii-infected mice (46). In these instances of in vivo sensitization, IgM, IgG, and complement have all been found on the red cell surface in varying combinations. Although none of the antigens were purified or characterized, antigen alone did not appear to bind to erythrocytes. Antigenantibody complexes were formed and bound to the red cells of these patients and animals. ${ }^{51} \mathrm{Cr}$-labeled erythrocytes were concentrated in the spleens of these patients. An asplenic patient with kala azar did not develop anemia despite heavy infection (45). Acute hemolysis with positive direct antiglobulin test has also been reported in three children after diphtheria-pertussistetanus vaccination (47). Both tetanus and diphtheria toxoids bind to erythrocytes, but hemolytic complications are exceedingly rare.

The fate of red blood cells in immune hemolysis depends upon the type, biological activity, and density of antigen and antibody upon the surface of the erythrocyte (48). In guinea pigs, IgM-coated cells are rapidly sequestered in the liver, and a proportion of these cells are released into the circulation over the next 1-2 h (49). IgM clearance requires complement activation. IgG mediates clearance directly and by activation of the classical pathway of complement. Both liver and spleen are sites of destruction of erythrocytes and other particles coated with IgG.

In addition to different mechanisms and patterns of clearance of IgM- and IgG-coated erythrocytes, the molecular form of C3 affects the fate of sensitized cells (50). C3b-coated cells are rapidly cleared. The antigen-antibody-C3d complex is removed by hepatic macrophages from the surface of the red cell, which is then returned to the circulation. 
The initial antibody response during primary infection is predominantly IgM. IgG antibody may be present if the patient has had previous exposure to related antigens. Hemolysis occurring early in the course of $H$. influenzae type b disease appears to require complement fixation by immunoglobulin bound to PRP-sensitized erythrocytes to induce extravascular clearance by hepatic and splenic macrophages, intravascular hemolysis by terminal complement components, or both. PRP alone induces rapid clearance of some cells, perhaps by inducing the abnormal deformability of erythrocytes found in some patients with $H$. influenzae type $b$ disease (13). Binding of bacterial products to the surface of the red blood cell is not unique to $H$. influenzae type $b$, and can be expected to induce hemolysis in other infections as well. The significance of hemolysis in invasive infection owing to this organism appears to be markedly enhanced by the frequent occurrence of prolonged antigenemia coinciding with production of specific antibody to PRP.

\section{Acknowledgment}

This study was supported by grant AI-16060 from the National Institutes of Health.

\section{References}

1. Neter, E. 1956. Bacterial hemagglutination and hemolysis. Bacteriol. Rev. 20:166-188.

2. Boyden, S. V. 1951. The adsorption of proteins on erythrocytes treated with tannic acid and subsequent hemagglutination by anti-protein serum. J. Exp. Med. 93:107-117.

3. Keough, E. V., E. A. North, and M. F. Warburton. 1947. Haemagglutinins of the Haemophilus group. Nature (Lond.). 160:63.

4. Quinn, P. H., F. J. Crosson, Jr., J. A. Winkelstein, and E. R. Moxon. 1977. Activation of the alternative complement pathway by Haemophilus influenzae type b. Infect. Immun. 16:400-402.

5. Anderson, P., G. Peter, R. B. Johnston, Jr., L. H. Wetterlow, and D. H. Smith. 1972. Immunization of humans with polyribophosphate, the capsular antigen of Haemophilus influenzae type b. J. Clin. Invest. 51:39-44.

6. Robbins, J. B., J. C. Parke, Jr., R. Schneerson, J. K. Whisnant. 1973. Quantitative measurement of "natural" and immunization-induced Haemophilus influenzae type b capsular polysaccharide antibodies. $\mathrm{Pe}$ diatr. Res. 7:103-110.

7. Smith, D. H., G. Peter, D. L. Ingram, A. L. Harding, and P. Anderson. 1973. Responses of children immunized with the capsular polysaccharide of Haemophilus influenzae type b. Pediatrics. 52:637644.

8. Peltola, H., H. Kayhty, M. Virtanen, and P. H. Makela. 1984. Prevention of Hemophilus influenzae type $\mathrm{b}$ bacteremic infections with the capsular polysaccharide vaccine. N. Engl. J. Med. 310:1561-1566.

9. Turner, E. K. 1948. Haemophilus influenzae meningitis in forty infants treated with sulfonamides, type specific antiserum and penicillin at the Children's Hospital, Melbourne. Med. J. Aust. 2:745-749.

10. Schiavone, D. J., and S. D. Rubbo. 1953. Anaemia associated with Haemophilus influenzae meningitis. Lancet. ii:696-698.

11. Margolis, J. 1955. Haemolytic anaemia in Haemophilus influenzae meningitis treated with specific rabbit serum. Med. J. Aust. 1:912-920.

12. Kaplan, K. M., and F. A. Oski. 1980. Anemia with Haemophilus influenzae meningitis. Pediatrics 65:1101-1104.

13. Sills, R. H., M. T. Caserta, and S. A. Landaw. 1982. Decreased erythrocyte deformability in the anemia of bacterial meningitis. J. Pediatr. 101:395-398.

14. O'Brien, R. T., J. I. Santos, L. Glasgow, and S. A. Landaw. 1981. Pathophysiologic basis for anemia associated with Haemophilus influenzae meningitis: preliminary observations. J. Pediatr. 98:928-931.
15. Weller, P. F., A. L. Smith, P. Anderson, and D. H. Smith. 1977. The role of encapsulation and host age in the clearance of Haemophilus influenzae bacteremia. J. Infect. Dis. 125:34-41.

16. Anderson, P., and D. H. Smith. 1977. Isolation of capsular polysaccharide from culture supernatants of Haemophilus influenzae type b. Infect. Immun. 15:472-477.

17. Anderson, P., R. B. Johnson, Jr., and D. H. Smith. 1972. Human serum activities against Haemophilus influenzae, type b. J. Clin. Invest. 51:31-38.

18. Anderson, P., R. B. Johnston, Jr., and D. H. Smith. 1973. Methodology in detection of human serum antibodies to Haemophilus influenzae type b. In Hemophilus influenzae. S. H. Sell and D. T. Karzon, editors. Vanderbilt University Press, Nashville TN. 87-94.

19. Davis, C. A., S. B. Shurin, and B. L. Congeni. 1983. Neutrophil function in a patient with meningococcal meningitis and complement (C7) deficiency. Am. J. Dis. Child. 137:404-406.

20. Newman, R. B., R. W. Stevens, and H. A. Gaafar. 1970. Latex agglutination test for diagnosis of Haemophilus influenzae type $\mathrm{b}$ meningitis. J. Lab. Clin. Med. 76:107-113.

21. O'Reilly, R. J., P. Anderson, D. L. Ingram, G. Peter, and D. H. Smith. 1975. Circulating polyribophosphate in Hemophilus influenzae, type b meningitis: correlation with clinical course and antibody response. J. Clin. Invest. 56:1012-1022.

22. Boyüm, A. 1968. Isolation of mononuclear cells and granulocytes from human blood. Scand. J. Clin. Lab. Invest. 21:77-89.

23. Mendes, N. F., M. A. E. Tolnai, N. P. A. Silveira, R. B. Gilbertson, and R. S. Metzgar. 1973. Technical aspects of the rosette tests used to detect human complement receptor (B) and sheep erythrocyte-binding (T) lymphocytes. J. Immunol. 111:860-867.

24. Stossel, T. P., R. J. Mason, J. Hartwig, and M. Vaughan. 1972. Quantitative studies of phagocytosis by polymorphonuclear leukocytes: use of emulsions to measure the initial rate of phagocytosis. J. Clin. Invest. 51:615-624.

25. Guest, G. M., and E. W. Brown. 1957. Erythrocytes and hemoglobin of the blood in infancy and childhood. III. Factors in variability, statistical studies. Am. J. Dis. Child. 93:486-509.

26. Diem, K., editor. 1962. Scientific Tables. Documenta Geigy, 6th edition. Geigy Pharmaceuticals. Ardsley, NY. 32-35.

27. Sutton, A., R. Schneerson, S. Kendall-Morris, and J. B. Robbins. 1982. Differential complement resistance mediates virulence of Haemophilus influenzae type b. Infect. Immun. 35:95-104.

28. Tarr, P. I., S. W. Hosea, E. J. Brown, R. Schneerson, A. Sutton, and M. M. Frank. 1982. The requirement of specific anticapsular IgG for killing of Haemophilus influenzae by the alternative pathway of complement activation. J. Immunol. 128:1772-1775.

29. Corrall, C. J., J. A. Winkelstein, and E. R. Moxon. 1982. Participation of complement in host defense against encapsulated Haemophilus influenzae types a, c, and d. Infect. Immun. 35:759-763.

30. Anderson, P., and R. A. Insel. 1981. A polysaccharide-protein complex from Haemophilus influenzae type b. I. Activity in weanling rabbits and human T lymphocytes. J. Infect. Dis. 144:509-520.

31. Anderson, P., J. Pitt, and D. H. Smith. 1976. Synthesis and release of polyribophosphate by Haemophilus influenzae type $\mathrm{b}$ in vitro. Infect. Immun. 13:581-589.

32. Boyden, S. V. 1953. Fixation of bacterial products by erythrocytes in vivo and by leukocytes. Nature (Lond.). 171:402-403.

33. Chi-Yen Chu, D., and R. E. Hoyt. 1954. Reactions of T Vi and Ballerup Vi Haptenes with antisera against Vi-coated erythrocytes. $J$. Hyg. 52:100-104.

34. Buxton, A. 1959. The in vivo sensitization of avian erythrocytes with Salmonella gallinarum polysaccharide. Immunology. 2:202-3.

35. Young, V. M., H. C. Gillem, and J. H. Akeroyd. 1962. Sensitization of infant red cells by bacterial polysaccharides of Escherichia coli during enteritis. J. Pediatr. 60:172-176.

36. Warren, J. R., A. S. Harris, and C. H. Wallas. 1983. Transformation of human erythrocyte shape by endotoxic lipopolysaccharide. Infect. Immun. 39:431-434.

37. Neter, E., O. Westphal, O. Luderitz, E. A. Gorzynski, and E. 
Eichenberger. 1956. Studies of enterobacterial lipopolysaccharides: effects of heat and chemicals on erythrocyte-modifying, antigenic toxic, and pyrogenic properties. J. Immunol. 76:377-385.

38. Shumway, C. N., and D. Pollock. 1965. The effect of a pneumococcal product upon rabbit erythrocytes in vitro and in vivo. J. Lab. Clin. Med. 65:432-439.

39. Abdalla, S., D. J. Weatherall, S. N. Wickramasinghe, and M. Hughes. 1980. The anaemia of $P$. falciparum malaria. Br. J. Haematol. 46:171-183.

40. Woodruff, A. W., V. E. Ansdell, and L. E. Pettitt. 1979. Cause of anaemia in malaria. Lancet. i:1055-1057.

41. Abdalla, S., and D. J. Weatherall. 1982. The direct antiglobulin test in P. falciparum malaria. Br. J. Haematol. 51:415-425.

42. Facer, C. A. 1980. Direct Coombs antiglobulin reactions in Gambian children with Plasmodium falciparum malaria. II. Specificity of erythrocyte-bound IgG. Clin. Exp. Immunol. 39:279-288.

43. Facer, C. A., R. S. Bray, and J. Brown. 1979. Direct Coombs antiglobulin reactions in Gambian children with Plasmodium falciparum malaria. I. Incidence and class specificity. Clin. Exp. Immunol. 35:119127.

44. Woodruff, A. W., J. L. Ziegler, A. Hathaway, and T. Gwata.
1973. Anaemia in African trypanosomiasis and "big spleen disease" in Uganda. Trans. R. Soc. Trop. Med. Hyg. 67:329-337.

45. Woodruff, A. W., E. Topley, R. Knight, and C. G. B. Downie. 1972. The anaemia of kala azar. Br. J. Haematol. 22:319-329.

46. Amole, B. O., A. B. Clarkson, Jr., and H. L. Shear. 1982. Pathogenesis of anemia in Trypanosoma brucei-infected mice. Infect. Immun. 36:1060-1068.

47. Haneberg, B., R. Matre, R. Winsnes, A. Dalen, H. Vogt, and P. H. Finne. 1978. Acute hemolytic anemia related to diphtheria-pertussis-tetanus vaccination. Acta Paediatr. Scand. 67:345-350.

48. Frank, M. M., A. D. Schreiber, J. P. Atkinson, and C. J. Jaffe. 1977. Pathophysiology of immune hemolytic anemia. Ann. Intern Med. 87:210-222.

49. Schreiber, A. D., and M. M. Frank. 1972. The role of antibody and complement in the immune clearance and destruction of erythrocytes. I. In vivo effects of $\mathrm{IgG}$ and IgM-complement fixing sites. J. Clin. Invest. 51:575-582.

50. Atkinson, J. A., and M. M. Frank. 1975. Studies on the in vivo effects of antibody: interaction of IgM antibody and complement in the immune clearance and destruction of erythrocytes in man. J. Clin. Invest. 54:339-348. 